ARTICLE

https://doi.org/10.1057/s41599-019-0365-z

\title{
Sharing the same languages helps us work better together
}

\author{
W. Quin Yow (i) ${ }^{1 \star} \&$ Tony Zhao Ming $\operatorname{Lim}^{1}$
}

\begin{abstract}
Collaborative problem-solving, the mutual engagement of people in a coordinated effort to solve a problem together, plays a critical role in the increasingly complex, linguistically diverse, and interconnected world. In particular, being able to communicate in the same languages provides a critical platform for facilitating problem solving among members of a multilingual team. Little research has explored whether sharing the same spoken languages would boost collaborative problem-solving over and beyond the effects of possible confounding variables such as language proficiency, personality, ethnicity, nationality, and non-verbal intelligence. This study manipulated the sharing of same languages by pairing 118 English-speaking bilingual participants either with someone who shares the same two spoken languages as themselves (English-same pair) or with someone who differs in one language (English-different pair). We explored whether such sharing of the same languages enhances collaborative problem-solving in multilingual pairs. Participants completed the Raven's Matrices individually, as well as an insight problem-solving task (Triangle of Coins task) and a divergent thinking task (Mind-mapping) in pairs. English-same pairs performed better than English-different pairs in the insight problem-solving task but not in the divergent thinking task. English-different pairs collaborated (mean number of turns per minute) and communicated (mean number of utterances) more than English-same pairs in the divergent thinking task, although the effect of pair type on communication was fully mediated by a difference in ethnicity within pairs. More collaboration could have been needed between English-different pairs in the divergent thinking task to achieve comparable performance as English-same pairs, possibly due to the different communication processes experienced by English-different pairs. This study provides insights to the role of sharing spoken languages in enhancing collaborative problem-solving in small multilingual groups.
\end{abstract}

\footnotetext{
${ }^{1}$ Singapore University of Technology and Design, Singapore 487372, Singapore. *email: quin@sutd.edu.sg
} 


\section{Introduction}

W orking in small groups becomes increasingly crucial as problems become more complex. Working collaboratively on problems, or collaborative problem-solving, is defined as the mutual engagement of participants in a coordinated effort to solve a problem together (Roschelle and Teasley, 1995). This is different from cooperative work, or tasks that the labor is divided but then completed individually (Dillenbourg, 1999; Roschelle and Teasley, 1995). For example, in mathematical problem-solving, if one person does the first subpart and the other does the second subpart, this would be termed as cooperative work. However, if both people work together to solve the problems together, this would be termed as collaborative work. Thus, collaboration requires mutual engagement of the group, where members of the group work together and perform actions toward a common goal (Dillenbourg, 1999; Roschelle and Teasley, 1995). But successful mutual engagement of the group hinges on the members' ability to communicate with each other during the problem-solving process. With the rising importance of collaborative problem-solving in multilingual and multicultural work or study teams today, stemmed in part from an increasing majority of the world's population who speaks two or more languages (Crystal, 1997; Ripoll et al., 1995; Springer et al., 1999; U.S. Census Bureau, 2010), being able to communicate in the same languages provides a critical platform for facilitating problem solving among these teams. This study aims to explore the effect of similarities in spoken language between members of a team on collaborative problem-solving performance.

Collaborative problem-solving in small groups has shown multiple benefits over working as individuals in problem-solving tasks (e.g., Arterberry et al., 2007; Barron, 2000; Kwon and Cifuentes, 2009; Phelps and Damon, 1989). Barron (2000) showed that students who worked in teams outperformed individuals in problem-solving and planning tasks. Kwon and Cifuentes (2009) further showed that computer-based concept maps that were collaboratively created by students were more deeply conceptualized than concept maps that were created by individual students. Even 5-year-olds performed better with a partner than when working alone on puzzle problems, especially if they know that their performance would be evaluated (Arterberry et al., 2007).

Past studies have examined various factors that could impact collaborative problem-solving in small groups. Webb and colleagues (1995) showed that providing explanations instead of only the right answer and engaging in constructive activity aided collaborative mathematical learning in self-directed groups. Woolley and colleagues (2008) showed the importance of having expert members and collaborative planning in small-group collaborative problem-solving (note: engaging only in collaborative planning or having expert members alone did not improve collaborative problem-solving). Having expert members in a team is consistent with the notion that diversity in teams could be beneficial. An early study by Hoffman and Maier (1961) found that significantly more heterogenous groups (diverse groups that varied in personality and gender) produced high quality solutions compared to homogenous groups (less-diverse groups; $65 \%$ vs. $21 \%)$. Furthermore, greater diversity in problem-solving styles within teams could improve collaborative problem-solving (Kurtzberg, 2005; Thornburg, 1991; Villa et al., 1996; Woodman et al., 1993). For example, graduate and organizational teams consisting of members with both structured and unstructured problem-solving styles were found to have more creative ideas on a collaborative idea generation task than teams that comprised solely members with either structured or unstructured problemsolving styles (Kurtzberg, 2005). Similarities among group members could also boost collaborative problem-solving
(Canham et al., 2012; Curşeu and Pluut, 2013; Harrison et al., 2002; Staples and Zhao, 2006). Harrison and colleagues (2002) showed more favorable outcomes for work teams who had surface-level and deep-level similarities than those who had not. Interestingly, Curşeu and Plutt (2013) found that while gender and nationality diversity had positive effects on collaborative learning and problem-solving, variety in teamwork-related expertize had indirect negative effects on the quality of teamwork processes. Thus, past studies demonstrated that the characteristics that the team members shared or did not share with each other can differentially impact on the problem-solving process and performance outcomes.

Another characteristic that plays an important role in collaborative problem-solving is language. The specific role of sharing the same languages on collaborative problem-solving has not been previously studied directly, but past literature suggests that similarities in language between participants can have positive effects on collaborative problem-solving through better quality of communication and affiliation (e.g., McLeod et al., 1996). Language provides a medium for communication, sharing of ideas and working on ideas through mutual engagement between small groups and teams (e.g., Baldo et al., 2005; Kempert et al., 2011; Mercer, 1996). Communication has been shown to be critical in collaborative problem-solving processes by facilitating interaction and collaboration among members of the team. Ross and Raphael (1990) demonstrated that student communication was positively related to performance in collaborative problem-solving, especially when the collaborative processes were structured. Dossick and Neff (2011) further showed that communication of ideas led to more effective problem-solving among small groups.

Language is also crucial in collaborative problem-solving as it could increase the level of affiliation between members of the team through shared identity, thus making them feel more comfortable with each other and improving the quality of the collaboration (e.g., Noels et al., 1996). Shepard (1964) postulated that similarity aids in developing cohesion among work teams, and cohesion in turn is associated with the success of a group. For example, although ethnically diverse teams had better quality work in a brainstorming task, members of these teams were emotionally closer to members of another team who shared the same language and ethnicity background as themselves (McLeod et al., 1996). Relating to the prior work reviewed earlier, having diversity in a team might not benefit collaborative problemsolving if there is reduced cohesiveness. In Curseu and Plutt's study (2013), the diversity in teamwork-related expertise might have caused interpersonal conflict and reduced affiliation, which in turn led to indirect negative effects on team performance. Since past studies suggest that language promotes interaction and bonding between members of a group, sharing the same languages might attenuate any potential conflict felt between members (e.g., expert vs. non-expert members). Particularly in this study, sharing the same spoken languages might facilitate communication and collaboration between members for better problem-solving outcomes, and help remediate against any possible negative effects of existing diversities (e.g., nationality and ethnicity) to create positive outcomes on collaborative problemsolving (e.g., Harrison and Klein, 2007; Woolley et al., 2008).

In this study, our measurement of both communicative and collaborative processes was obtained through audio recordings, which is consistent with past studies (Edelsky, 1981; Harris et al., 2009; Harris et al., 2008; Kannampallil et al., 2016; Rice et al., 2010). For example, Harris and colleagues (2009) used mean number of utterances obtained from audio recordings to represent communication in their study that explored participants' interactions with single-touch surfaces and multi-touch surfaces, 
while Edelsky (1981) defined the mean number of turns per minute obtained from audio recordings as a measure of collaboration between adults. A turn refers to the start of when someone begins talking and ends when someone else takes over. The number of turns per minute has been used in previous studies to measure collaboration (e.g., Edelsky, 1981; Isaacs and Tang, 1994; Kruger, 1993). Thus, we quantified communicative processes as the mean number of utterances per minute and collaboration as the mean number of turns per minute in our study. We also coded for implicit communication processes within each pair, e.g., how much the pairs spoke the same two languages, how similar the pairs were in accent, and how comfortable the pairs appeared to be in their communication with each other (e.g., Gluszek and Dovidio, 2010; Paradis, 1998).

Language can have a positive effect on problem-solving even when the language status of the participants was not made known explicitly to individual participants (e.g., Bialystok and Majumder, 1998; Cushen and Wiley, 2011; McLeod et al., 1996; Wright and Lander, 2003). Cushen and Wiley (2011) showed that bilinguals did better than monolinguals in an insight problemsolving task when the language status of the participants was not made known explicitly. Similarly, Bialystok and Majumder (1998) found that balanced bilinguals (bilinguals that were equally proficient in both languages) showed better performance in linguistic and non-linguistic tasks than partial bilinguals and monolinguals in a group of Grade 3 students. The language status of the participants was also not made known to the group. In this study, we extend this by exploring the effect of sharing the same languages in bilingual pairs when the language status is not made known to the participants in the pair. To help isolate the effects of sharing the same languages on the performance in the collaborative problem-solving tasks, we randomly paired English-speaking bilingual participants into two conditions (namely, English-same language pairs or English-different language pairs) so that other existing variables such as ethnicity, gender and personality would be randomly distributed across the two conditions. English-same language pairs referred to English-speaking pairs who shared the same second language, and English-different language pairs referred to English-speaking pairs who spoke English and a different second language. We also noted that explicitly revealing the language status of the participants might lead to participants second-guessing the aims of the study and changing the way they behave to fit what they believe is the purpose of the study.

In addition to random sampling and random assignment, the effects of other existing variables would also need to be explored. Firstly, as the study is carried out in English, the differences in English spoken proficiency between team members could affect their performance in terms of how well they understood the task and how well they could express their ideas and communicate with each other. Differences in English spoken proficiency has been shown to affect collaborative efforts in studies where English was used (e.g., Neeley et al., 2009). Secondly, personality could also play a role in affecting how conscientious participants are in completing the task, how agreeable they are with each other, how open they are to novel ideas, how much they interact with each other and how much positivism they bring to the task. Personality has been shown to be associated with collaborative problem solving (e.g., Halfhill et al., 2005; Kickul and Neuman, 2000; Maltzman et al., 1956). Kickul and Neuman (2000) found that conscientiousness and cognitive ability were associated with team performance among undergraduate students in mixed gender teams. Halfhill and colleagues (2005) further showed that agreeableness, emotional stability and helpfulness had positive effects in collaborative work environments. The same study (Halfhill et al., 2005) also found that the more heterogenous the group was on personality traits, the more problem-solving performance would decrease. Thirdly, the nationality and ethnicity of the participants could also play a role in collaborative problemsolving. Participants with the same ethnicity and nationality might feel more comfortable with each other leading to better collaboration in the problem-solving tasks. However, differing effects of diverse ethnicities and nationalities on collaborative work teams were found in previous studies (e.g., McLeod et al., 1996; Terenzini et al., 2001; Wright and Lander, 2003). McLeod and colleagues (1996) discovered that work teams with medium ethnic diversity did significantly better than work teams with no ethnic diversity. But Wright and Lander (2003) found that teams with nationality diversity were more inhibited in terms of their verbal participation when collaborating on problem-solving tasks than teams with no nationality diversity, which leads to worse outcomes in these mixed teams. Lastly, the level of individual non-verbal intelligence could affect how fast the participants complete the insight problem-solving task, as well as the number of novel ideas they can come up with in the divergent thinking task. Higher non-verbal intelligence was shown to result in better problem-solving in past literature (e.g., Hayslip and Sterns, 1979; Resnick and Glaser, 1976). Hayship and Sterns (1979) found that fluid intelligence was related to problem-solving involving abstract stimuli. Thus, these five extraneous variables, spoken English proficiency, personality, nationality, ethnicity, and nonverbal intelligence were also examined in this study.

For this study, two types of collaborative problem-solving tasks were selected-a collaborative insight problem-solving task and a collaborative divergent thinking task. These tasks required different levels of collaboration between participants (see also Nelson, 1999, for a discussion on problem-based vs. cooperative-based tasks, and Care et al., 2015, on content-free vs. content-dependent tasks). A Triangle of Coins Task was chosen as the insight problem-solving task and a mindmapping task was chosen as the divergent thinking task. The Triangle of Coins task requires participants to flip a triangle of ten coins around by moving only three coins. The dependent variable is the time taken to complete the task. The task requires a low level of collaboration between participants as the answer could be derived through individual processes like personal insight. The mind-mapping task requires participants to brainstorm and generate as many ideas as possible on a given problem. The dependent variable is the number of novel and unique ideas that are produced by the participants (Srivathsavai et al., 2010). This task requires a high level of collaboration between participants to come up with as many novel solutions as possible. Exploring the effects of sharing the same languages on both of these tasks will allow for greater insights into tasks that require differing levels of collaboration. As described earlier, we also explored the level of communication and collaboration that is carried out during these tasks as measured by the number of utterances and number of turns as exhibited by the participants respectively.

In sum, we hypothesized that bilingual participants who share the same two languages would overall perform better in collaborative problem-solving tasks than those who do not, taking into account the differing communicative and collaborative processes between pairs of participants, over and beyond the effects of language proficiency, personality, ethnicity, nationality, and nonverbal intelligence.

\section{Methods}

The study received approval and was conducted in compliance with the ethical guidelines prescribed by the author's university's Institutional Review Board (IRB). All participants provided written informed consent prior to their participation. 
Participants. One hundred and eighteen healthy bilingual undergraduate students (68 males, $M_{\text {age in years }}=22.22, S D=1.92$, range $=18$ to 28 ) were recruited from a local university. Participants had to fulfill the following inclusion criteria: (1) be 18 years old and above; (2) speak English and another language, (3) and have normal or corrected-to normal vision with no color blindness.

Participants provided information on their parents' highest educational level $(1=$ None; $2=$ Primary School; $3=$ Secondary School; $4=$ Junior College; $5=$ Some University, not completed; $6=$ University Degree; $7=$ Postgraduate Degree; father: $M=4.90 ; S D=1.51$; mother: $M=4.64 ; S D=1.53)$, household monthly income $(1=\mathrm{S} \$ 0$ to $\mathrm{S} \$ 1000 ; 2=\mathrm{S} \$ 1001$ to $\$ \$ 2000 ; 3=\mathrm{S}$ $\$ 2001$ to $S \$ 3000 ; 4=S \$ 3001$ to $S \$ 4000 ; 5=S \$ 4001$ to $S \$ 5000$; $6=\mathrm{S} \$ 5001$ to $\mathrm{S} \$ 6000 ; 7=\mathrm{S} \$ 6001$ to $\mathrm{S} \$ 7000 ; 8=\mathrm{S} \$ 7001$ to $\mathrm{S}$ $\$ 8000 ; 9=\mathrm{S} \$ 8001$ to $\mathrm{S} \$ 9000 ; 10=\mathrm{S} \$ 9001$ and above; $M=5.77$; $S D=3.36$ ), ethnicity (Chinese, Malay, Indian, or Others) and nationality (native or non-native). Of the 118 participants, 98 were Chinese, 3 were Malay, 6 were Indian, and 11 were Others. Sixty-nine of the participants were native citizens and 49 were non-native citizens.

Participants provided information on their language status (refer to section on Language background questionnaire), including their language proficiency. All participants were proficient in English. Bilingual participants were randomly paired up into same or different language pairs based on the second language (other than English) they were proficient in. Englishsame language pairs consisted of English-speaking participants who shared the same second language (e.g., English and Mandarin). English-different language pairs were participants who shared one language (i.e., English) but differed in their second language (e.g., Mandarin vs. Malay). In total, there were 31 English-same language pairs (all pairs spoke EnglishMandarin) and 28 English-different language pairs (see Table 1 for the breakdown of languages spoken by different language pairs). In addition, all pairs were of the same gender as past literature found that teams made up of mixed gender performed worse in collaborative problem-solving tasks (Strough et al., 2001; Webb, 1984), where females in these mixed teams were shown to perform worse than males on the collaborative problem-solving tasks. In total, there were 34 male language pairs (20 Englishsame language pairs and 14 English-different language pairs) and 25 female language pairs (11 English-same language pairs, 14 English-different language pairs).

\section{Table 1 Breakdown of languages spoken by bilingual participants of english-different language pairs.}

\section{Language of 1st participant}

\section{Language of 2 nd} participant

English-Bahasa Indonesia

English-Vietnamese

English-Bengali

English-Hindi

English-Tamil

English-Malay

English-Korean

English-Burmese

English-Thai

English-Bahasa Indonesia

Total
Number of pairs

5

7

2

3

4

3

1

1

1

28
Note: The languages of the first participant and second participant in the English-different language pairs are presented in the table. For example, there were 5 English-different language pairs that had one participant who spoke English-Mandarin and the other who spoke English-Bahasa Indonesia

\section{Materials}

Background variables. Language background questionnaire: Participants completed a language background questionnaire that contained items on demographics (such as age, gender, nationality and ethnicity) and items to derive participants' individual language background (e.g., languages known, proficiency of each language). To gauge language proficiency, we asked participants to name each of the languages they knew and rate how proficient they were in speaking each language, on a ten-point scale (from $1=$ not proficient, to $10=$ very proficient). Proficiency in speaking English was used as a measure of language proficiency in this study due to the nature of the study where participants would collaborate with their partner to perform the required tasks mostly through speaking English with each other.

For demographic variables, to control for potential differences in ethnicity and nationality, we coded the difference in ethnicity of participants within pairs (Same Ethnicity: $0=$ if participants in pair share the same ethnicity; $1=$ if participants in pair are of different ethnicity) and the difference in nationality of participants within pairs (Same Nationality: $0=$ participants in pair share the same nationality; $1=$ participants in pair are of different nationality).

Big five inventory: Participants were given the Big Five Inventory (John and Srivastava, 1999) as a measure of personality traits. The Big Five Inventory consists of 44 items on five personality traits: Openness, Extraversion, Conscientiousness, Agreeableness, and Conscientiousness. Participants rated themselves based on how much the characteristics as described in the items apply to themselves from a scale of 1 (disagree strongly) to 5 (agree strongly). Examples of these items include "can be tense" and "is outgoing, sociable". The Big Five Inventory has shown good reliability and validity in the literature with a reported coefficient alpha reliability of about 0.80 for all its dimensions ( $\mathrm{Li}$ et al., 2015). The difference in each of the five personality traits within pairs (e.g., Same Openness: difference in rating scores in Openness between first and second participant) was derived.

Raven's progressive matrices: We used the Raven's Progressive Matrices (Raven et al., 2004) as a measure of non-verbal fluid intelligence. In this task, participants are required to choose one out of six figures that completes a pattern. The Raven's Progressive Matrices Task was administered using a laptop PC. Visual stimuli were presented to participants from a distance of about $70 \mathrm{~cm}$ via a 20 -inch monitor with a refresh rate of about $60 \mathrm{~Hz}$. Instructions for the computerized tasks were presented on screen in English. A standard QWERTY keyboard was used to respond to the tasks. Participants were instructed to respond as quickly and as accurately as possible. Participants pressed the number key on the keyboard that corresponded with their selection. There was a total of 36 items and participants were given 10 minutes to attempt as many as they could. The dependent variable (DV) in this task is the number of correct items completed within 10 minutes. Similarly, the difference in this DV within pairs (i.e., Same Non-verbal intelligence) was calculated.

Collaborative problem-solving tasks. Triangle of Coins task (insight problem-solving): We used the Triangle of Coins as the collaborative insight problem-solving task. Participants were asked to work together in pairs on the Triangle of Coins puzzle where they needed to flip a triangle of ten coins around by moving only three coins. Pairs who had prior knowledge of the Triangle of Coins puzzle were asked to complete an equivalent Matchstick task instead, where they would need to make seven squares by moving only two matchsticks based on a given array of matchsticks. The dependent variable of the collaborative insight problem-solving is the time taken for each pair of participants to complete the task 
(in seconds). Fifty-one pairs completed the coin task and 8 pairs completed the matchstick task. There was no significant difference in the time taken to complete the coin or matchstick task $(t$ $\left.(116)=0.56, p=0.58, \eta^{2}=0.002\right)$. Therefore, these tasks could be conceived as tasks of equivalent difficulty.

Mind-mapping task (divergent thinking task): The mindmapping task was used to measure the divergent thinking between pairs of participants. Both participants first watched a video that provided the basic principles of mind-mapping (SUTD-MIT International Design Centre, 2015). Next, they were asked to brainstorm ideas on a given problem (i.e., how to keep insects out of the house) and work collaboratively to come up with a mind-map of solutions. Divergent thinking is measured as the number of novel and unique ideas that are produced by the participants. The complexity of the mind-maps was taken into account as the ideas were first grouped into similar themes before selecting the ideas that represented novel and unique constructs so that ideas that represented the same themes were not doublecounted. One coder who spoke English as his first language (Coder A) coded all 59 mind-maps for the number of novel ideas produced by the participants. A second coder (Coder B) who similarly spoke English as his first language randomly chose half of the mind-maps (30 mind-maps) and coded the mind-maps in the same way for the number of novel ideas produced by participants. Split-half inter-rater reliability test showed significant intra-class correlations for the number of novel ideas generated in the divergent thinking task $(\operatorname{ICC}(3,2)=0.94, p<$ 0.001 ). Thus, there was a significant agreement (94\%) between the two coders on the number of novel ideas generated for the mindmaps.

Audio recordings: Audio recordings were taken of the conversations within the pairs during the insight problemsolving and the divergent thinking tasks. Of all the 59 sets of audio recordings, 56 sets of audio recordings ( 3 corrupted files) were coded by Coder A for the number of utterances and the number of turns. Coder B randomly chose half of the recordings (28 recordings) and similarly coded the recordings. Mean number of utterances per minute (as a measure of communication) and mean number of turns per minute (as a measure of collaboration) were then calculated. Split-half inter-rater reliability test showed significant intra-class correlations for the mean number of utterances per minute in the insight problem-solving task and the divergent thinking task $(\operatorname{ICC}(3,2)=0.97, p<0.001$ and ICC $(3,2)=0.81, p<0.001$, respectively), and the mean number of turns per minute in the insight problem-solving task and divergent thinking task $(\operatorname{ICC}(3,2)=0.95, p<0.001$ and ICC $(3,2)=0.76, p<0.001$, respectively). The coders had significant agreement (76 to $97 \%$ ) on the number of utterances and turns made between the same language and different language pairs.

Unidentified copies of the audio recordings were further rated by an independent blind coder who spoke English as his first language to explore the implicit communication between pairs of participants during the tasks, such as "How similar were participants in accent?" and "How comfortable were the participants with each other?" from a scale of 1-10, and "Did participants sound like they speak the same two languages?" (0-“no", 1-“yes") (e.g., Gluszek and Dovidio, 2010; Paradis, 1998). A second independent blind coder who also spoke English as his first language coded $50 \%$ of the data. Split-half inter-rater reliability test revealed significant intra-class correlations (ICC (3, $2)>0.62$, all $p s<0.001)$ : the coders had significant agreement (above 62\%) for the implicit communication variables coded.

Procedure. All tasks were administered individually in a quiet room. Participants completed the background language questionnaire and were paired into same or different language pairs based on the languages they spoke. Participants then completed the Raven's Progressive Matrices Task individually and the Triangle of Coins or Matchstick Task and the Mind-mapping task in pairs. We audiotaped conversations between the participants while they completed the two collaborative tasks. The order of the three tasks was counterbalanced across participants. The entire session took about one hour.

\section{Results}

There were no significant differences found between male and female pairs in performance, communication, and collaboration on the insight problem-solving task and the divergent thinking task (all $p s>0.10 ; \eta^{2}<0.28$ ), so we collapsed the data across gender. One-way ANOVAs were performed on the pairs' differences in English spoken proficiency, nationality, ethnicity, bigfive personality factors, and non-verbal intelligence across pair type (same or different language). The significant variables were then subsequently controlled for (see Table 2).

English-same language pairs were found to be more homogeneous in self-reported English spoken proficiency $(F(1$, $\left.112)=6.93, p=0.01, \eta^{2}=0.06\right)$, ethnicity $(F(1,116)=70.33, p<$ $\left.0.001, \eta^{2}=0.38\right)$ and agreeableness $(F(1,110)=4.48, p=0.04$ $\left.\eta^{2}=0.04\right)$ than English-different language pairs. No other significant differences were found. No multicollinearity was found between pair type and the three variables ( $r s<0.62$; all VIFs $=1.00)$. The three variables were controlled for in subsequent analysis.

\section{Overall task performance}

Pair type and insight problem-solving task. Hierarchical multiple regressions were carried out to explore the unique effects of pair type on the time taken to solve the insight problem-solving task. The three variables, within-pair differences in English spoken proficiency, ethnicity of participants and agreeableness, were entered as Step 1 of the hierarchical multiple regression. Pair type ( $0=$ English-same language pairs; $1=$ English-different language pairs) was entered as Step 2 of the hierarchical multiple regression (see Table 3).

The four predictors accounted for $8.2 \%$ of the variance (Adjusted $R^{2}=0.05$ ) of the time taken to complete the insight problem-solving task. The model and the $R^{2}$ change were

\begin{tabular}{|c|c|c|c|c|}
\hline & \multicolumn{2}{|c|}{ Same language pairs } & \multicolumn{2}{|c|}{$\begin{array}{l}\text { Different language } \\
\text { pairs }\end{array}$} \\
\hline & $M$ & $S D$ & $M$ & $S D$ \\
\hline $\begin{array}{l}\text { Same English spoken } \\
\text { proficiency }\end{array}$ & $1.13^{\star}$ & 0.98 & $1.58^{\star}$ & 0.80 \\
\hline Same nationality & 0.42 & 0.50 & 0.54 & 0.50 \\
\hline Same ethnicity & $0.00^{\star}$ & 0.00 & $0.54^{\star}$ & 0.50 \\
\hline Same extraversion & 0.63 & 0.47 & 0.81 & 0.63 \\
\hline Same openness & 0.52 & 0.32 & 0.58 & 0.56 \\
\hline Same agreeableness & $0.48^{\star}$ & 0.44 & $0.68^{\star}$ & 0.54 \\
\hline Same conscientiousness & 0.68 & 0.42 & 0.72 & 0.50 \\
\hline Same neuroticism & 0.47 & 0.30 & 0.62 & 0.53 \\
\hline $\begin{array}{l}\text { Same non-verbal } \\
\text { intelligence }\end{array}$ & 0.67 & 0.49 & 0.74 & 0.48 \\
\hline
\end{tabular}

Note: The higher the score, the greater the difference is between a pair of participants * refers to significant differences between same and different language pairs on variables where ${ }^{\star} p<0.05,{ }^{\star \star} p<0.01,{ }^{\star \star \star} p<0.001$ 


\begin{tabular}{|c|c|c|c|}
\hline \multirow[t]{2}{*}{ Predictor } & \multicolumn{3}{|c|}{$\begin{array}{l}\text { Time taken to complete insight } \\
\text { problem-solving task }\end{array}$} \\
\hline & $\Delta R^{2}$ & $\beta$ & $t$ \\
\hline Step 1 & 0.01 & & \\
\hline Same English spoken proficiency & & -0.04 & -0.35 \\
\hline Same ethnicity & & 0.05 & 0.52 \\
\hline Same agreeableness & & 0.06 & 0.59 \\
\hline Step 2 & $0.08^{\star \star}$ & & \\
\hline Same English spoken proficiency & & -0.07 & -0.67 \\
\hline Same ethnicity & & -0.15 & -1.26 \\
\hline Same agreeableness & & 0.04 & 0.38 \\
\hline Pair type & & $0.35^{\star \star}$ & $2.90^{\star \star}$ \\
\hline Total $R^{2}$ & $0.08^{+}$ & & \\
\hline N & 108 & & \\
\hline
\end{tabular}

marginally statistically significant $(F(4,103)=2.30, p=0.06)$. Pair type was a significant predictor of the insight problemsolving task, $\beta=0.35, t(103)=2.90, p=0.005$. English-same language pairs $(M=87.48 \mathrm{~s}, S D=88.84 \mathrm{~s})$ were faster than English-different language pairs $(M=158.21 \mathrm{~s}, S D=159.31 \mathrm{~s})$ in completing the insight problem-solving task. All other variables were not found to be significantly associated with the time taken to complete the insight problem-solving task.

Pair type and divergent thinking task. Similar hierarchical multiple regressions were carried out to explore the unique effects of pair type on the total number of ideas generated on the divergent thinking task while the variables of differences in English spoken proficiency, ethnicity, and agreeableness of participants within pairs were controlled for.

Overall, the four predictors accounted for $11.9 \%$ of the variance (Adjusted $R^{2}=0.09$ ) in the total number of ideas generated on the divergent thinking task. The model was statistically significant, $F(4,103)=3.49, p=0.01$. Pair type did not predict the total number of ideas generated on the divergent thinking task, $\beta=-0.19, t(103)=-1.59, p=0.12$. Differences in agreeableness within pairs significantly predicted the total number of ideas generated $(\beta=0.32, t(103)=3.39, p=0.001)$. All the other variables were not significantly associated with the total number of ideas generated in the divergent thinking task.

Communication and collaboration. Communication amongst pairs was measured as the mean number of utterances per minute while collaboration was measured as the mean number of turns per minute within each pair. Table 4 provides a breakdown of the level of communication and collaboration in English-same and different language pairs.

Pair type and insight problem-solving task. Communication and collaboration: Similar hierarchical multiple regressions were carried out to explore the unique effects of pair type on the level of communication and the level of collaboration separately in the insight problem-solving task while controlling for the differences in English spoken proficiency, ethnicity of participants, and agreeableness within pairs. The models were not statistically significant, $F s>0.38$, $p s>0.56$. Pair type was not shown to predict communication or collaboration in the insight problem-solving task $(\beta s<-0.16, p s>0.24)$. No other significant effects were found ( $p s>0.20)$.
Table 4 Characteristics of English-same and Englishdifferent language pairs in communication (mean number of utterances per minute) and collaboration (mean number of turns per minute) between pairs.

\begin{tabular}{|c|c|c|c|c|}
\hline & \multicolumn{2}{|c|}{ Same language pairs } & \multicolumn{2}{|c|}{$\begin{array}{l}\text { Different language } \\
\text { pairs }\end{array}$} \\
\hline & M & $S D$ & $\mathbf{M}$ & $S D$ \\
\hline \multicolumn{5}{|c|}{ Insight problem-solving task } \\
\hline Communication & 14.43 & 5.93 & 14.38 & 6.90 \\
\hline Collaboration & 9.71 & 5.57 & 9.42 & 4.80 \\
\hline \multicolumn{5}{|c|}{ Divergent thinking task } \\
\hline Communication & $11.56^{\star \star \star}$ & 4.56 & $14.32^{\star \star \star}$ & 3.48 \\
\hline Collaboration & $6.70^{\star \star \star}$ & 2.90 & $9.04^{\star \star \star}$ & 2.13 \\
\hline
\end{tabular}

Table 5 Hierarchical multiple regression analysis comparing models of variables predicting the effect of pair type on the level of communication in the divergent thinking task.

\begin{tabular}{|c|c|c|c|}
\hline \multirow[t]{2}{*}{ Predictor } & \multicolumn{3}{|c|}{$\begin{array}{l}\text { Level of communication on the } \\
\text { divergent thinking task }\end{array}$} \\
\hline & $\Delta R^{2}$ & $B$ & $\mathbf{t}$ \\
\hline Step 1 & $0.20^{\star \star \star}$ & & \\
\hline Same English spoken proficiency & & $-0.26^{\star \star}$ & $-0.28^{\star \star}$ \\
\hline Same ethnicity & & $0.44^{\star \star \star}$ & $40.60^{\star \star \star}$ \\
\hline Same agreeableness & & -0.01 & -0.08 \\
\hline Step 2 & 0.01 & & \\
\hline Same English spoken proficiency & & $-0.27^{\star \star}$ & $-2.87^{\star \star}$ \\
\hline Same ethnicity & & $0.37^{\star \star}$ & $30.07^{\star \star}$ \\
\hline Same agreeableness & & -0.01 & -0.13 \\
\hline Pair type & & 0.11 & 0.91 \\
\hline Total $R^{2}$ & $0.21^{\star \star \star}$ & & \\
\hline N & 102 & & \\
\hline
\end{tabular}

Pair type and divergent thinking task. Communication: Hierarchical multiple regressions with the same control and independent variables were carried out to explore the unique effects of pair type on the level of communication in the divergent thinking task while controlling for the same three variables as above (see Table 5).

Overall, the four predictors accounted for $20.7 \%$ of the variance (Adjusted $R^{2}=0.17$ ) in the communication within pairs during the divergent thinking task. The model was found to be statistically significant $(F(4,97)=6.32, p<0.001)$. Pair type was not found to be a significant predictor of the level of communication in the divergent thinking task, $\beta=0.11, t$ $(97)=0.91, p=0.37$. However, the smaller the difference in English spoken proficiency, the more participants communicated within pairs in the divergent thinking task after pair type was added $(\beta=-0.27, t(97)=-2.87, p=0.005)$. Conversely, the pairs who were different in ethnicity communicated more within pairs in the divergent thinking task after pair type was added $(\beta=0.37, t(97)=3.07, p=0.003)$.

Further analyses on possible mediation effects found that the baseline relationship between pair type and the level of communication in the divergent thinking task was significant ( $F$ $(1,110)=12.67, \beta=0.32, t(110)=3.56, p=0.001)$. Pair type was also found to be significantly associated with differences in 


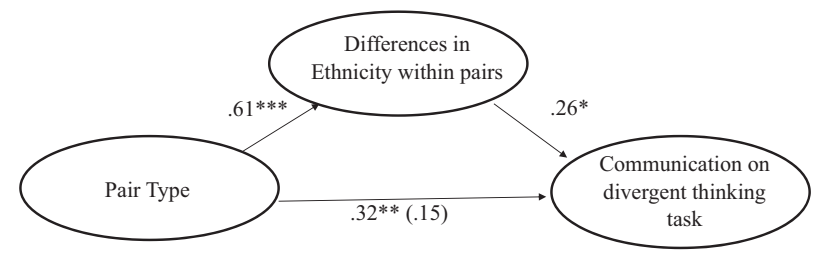

Fig. 1 Standardized regression coefficients for the relationship between pair type and communication in the divergent thinking task as mediated by difference in ethnicity. The standardized regression coefficient between pair type and communication, controlling for ethnicity, is in parentheses. ${ }^{*} p<$ $0.05,{ }^{\star \star} p<0.01,{ }^{\star \star \star} p<0.001$.

\begin{tabular}{|c|c|c|c|}
\hline \multirow[t]{2}{*}{ Predictor } & \multicolumn{3}{|c|}{$\begin{array}{l}\text { Level of collaboration in } \\
\text { divergent thinking task }\end{array}$} \\
\hline & $\Delta R^{2}$ & $\beta$ & $t$ \\
\hline Step 1 & $0.20^{\star \star \star}$ & & \\
\hline Same English spoken proficiency & & $-0.28^{\star \star}$ & $-20.98^{\star \star}$ \\
\hline Same ethnicity & & $0.43^{\star \star \star}$ & $4.50^{\star \star \star}$ \\
\hline Same agreeableness & & -0.01 & -0.05 \\
\hline Step 2 & $0.05^{\star}$ & & \\
\hline Same English spoken proficiency & & $-0.31^{\star \star}$ & $-3.36^{\star \star}$ \\
\hline Same ethnicity & & $0.25^{\star}$ & $20.13^{\star}$ \\
\hline Same agreeableness & & -0.02 & -0.18 \\
\hline Pair type & & $0.29^{\star}$ & $20.47^{\star}$ \\
\hline Total $R^{2}$ & $0.25^{\star \star \star}$ & & \\
\hline$N$ & 102 & & \\
\hline
\end{tabular}

ethnicity within pairs $(F(1,116)=70.33, \beta=0.61, t(116)=8.39$, $p<0.001)$. Pairs with different ethnicities were found to communicate significantly more than similar pairs in the divergent thinking task $(\beta=0.26, t(109)=2.20, p=0.03)$. Pair type and differences in ethnicity within pairs were found to jointly predict communication within pairs in the divergent thinking task $(F(2,109)=8.98, p<0.001)$, but pair type was no longer significantly associated with communication in the divergent thinking task $(\beta=0.15, t(109)=1.32, p=0.19)$ (refer to Fig. 1). Sobel tests revealed that the indirect effect was significant $(z=2.14, \mathrm{SE}=0.63, p=0.03)$. Difference in ethnicity within pairs was found to fully account for the relationship between pair type and communication in the divergent thinking task. No other significant effects were found.

Collaboration: The same hierarchical multiple regressions were carried out to explore the unique effects of pair type on the level of collaboration in the divergent thinking task (see Table 6). Holistically, the four predictors accounted for $24.7 \%$ of the variance (Adjusted $R^{2}=0.22$ ) in the mean number of turns per minute in the divergent thinking task. The model was statistically significant $(F(4,97)=7.95, p<0.001)$. Pair type was significant: English-different language pairs collaborated significantly more than English-same language pairs in the divergent thinking task, after taking into account the other three variables, $\beta=0.29, t$ $(97)=2.47, p=0.02$. Participants with smaller differences in English spoken proficiency within pairs were found to collaborate more in the divergent thinking task after pair type was added $(\beta=-0.31, t(97)=-3.36, p=0.001)$. Participants with greater differences in ethnicity within pairs were found to collaborate more in the divergent thinking task after pair type was added $(\beta=0.25, t(97)=2.13, p=0.04)$. No significant mediation effects were found.

Additional analysis on implicit communication. Additional analyses on the implicit communication between the pairs were conducted based on the coding of the audio recordings (see Table 7). One-way ANOVAs revealed that English-same language pairs were more similar in accent and sounded more like they spoke the same two languages than English-different language pairs in both the insight problem-solving task $(F(1,94)=11.30$, $p=0.001, \eta^{2}=0.11$, and $F(1,94)=5.47, p=0.022, \eta^{2}=0.06$, respectively) and the divergent thinking task $(F(1,94)=17.78$, $p<0.001, \eta^{2}=0.16$, and $F(1,94)=542.43, p<0.001, \eta^{2}=0.31$, respectively). This suggests that English-same language pairs might have experienced better quality communicative processes than English-different language pairs via implicit understanding of a common accent and language background.

\section{Discussion}

This study explored whether sharing the same two spoken languages would result in better performance in collaborative problem-solving tasks among bilingual adults than those who did not share the same languages. Our results suggest that sharing the same two spoken languages did enrich collaborative problemsolving in the insight problem-solving task, though these effects were not seen in the divergent thinking task. Communication and collaboration were explored as possible processes through which sharing the same languages would affect problem-solving in small groups. English-different language pairs collaborated more than English-same language pairs in the divergent thinking task. English-different language pairs also communicated more than English-same language pairs, though this was fully accounted for by a bigger difference in ethnicity within pairs. Independent coders determined that English-same language pairs indeed sounded more similar in accent and exhibited more similarities in language characteristics than English-different language pairs in both collaborative problem-solving tasks.

Our results indicated a greater amount of collaboration between English-different language pairs than English-same language pairs in the divergent thinking task although both pair types performed similarly in the task. We speculated that this additional collaboration might be needed by English-different language pairs to reach a comparable level of performance as English-same language pairs in the task. In particular, a divergent thinking task is expected to require a higher level of collaboration as participants are inclined to discuss and work together to find novel solutions compared to an insight problem-solving task. Perhaps not sharing the same two languages in a way "hindered" (or did not facilitate) the collaborative process, as Englishdifferent language pairs needed to take more turns per minute to share or clarify their ideas. Additional post-hoc analysis of the audio recordings revealed that two of the English-same language pairs (6.45\%) and six of the English-same language pairs (19.35\%) used both languages spontaneously with each other in the insight problem-solving task and divergent thinking task, respectively (note that participants were not explicitly told that their partner in the task shared or did not share the same second language as them). Interestingly, for three of the English-different language pairs $(10.7 \%$; one pair in insight problem-solving task and two pairs in divergent thinking task), one partner used another language with the other partner but stopped and switched back to English when they realized they did not get a clear response from their partner.

In comparison, in the insight problem-solving task, the positive effects of sharing the same two spoken languages became evident 
Table 7 Implicit communication indices for English-same and English-different language pairs.

\begin{tabular}{|c|c|c|c|c|c|}
\hline Task & Indices of implicit communication by coder & $\mathbf{M}$ & $S D$ & $\mathbf{M}$ & SD \\
\hline \multirow{2}{*}{ Insight problem-solving task } & Comfort & 7.12 & 1.15 & 7.33 & 0.95 \\
\hline & Speak the same 2 languages & $0.83^{\star}$ & 0.38 & $0.62^{\star}$ & 0.49 \\
\hline Divergent thinking task & Similarity in accent & $7.26^{\star \star \star}$ & 1.94 & $5.14^{\star \star \star}$ & 2.97 \\
\hline
\end{tabular}

as the English-same language pairs and English-different language pairs collaborated at equivalent levels but the English-same language pairs were more "efficient" in the collaboration process, thereby achieving similar shared mental models to solve the problem faster together than the English-different language pairs (Klimoski and Mohammed, 1994). Although we followed the procedure described in past studies to code for communication and collaboration (e.g., Edelsky, 1981; Gluszek and Dovidio, 2010; Isaacs and Tang, 1994; Kruger, 1993; Paradis, 1998), we noted that there could be further insights to the quality of the turns (such as constructive vs. disruptive turns), and by using other sources of data such as gestures and facial expressions. However, due to the limitation of our audio recordings, we were not able to further code for the quality of these turns. Future studies should consider using a richer platform to record the interactions between participants and code for a deeper level of interaction quality. Nevertheless, our results provided initial support to the hypothesis that sharing the same spoken languages could enhance problem-solving in small groups through better communicative and collaborative processes.

One could argue that the positive effect of sharing same languages on collaborative problem-solving did not stem from better communicative processes. Rather, it was the self-categorization effect that made the English-same language pairs feel closer and as part of a larger social group compared to the English-different language pairs (Turner, 1985; Turner et al., 1987). Selfcategorization theory predicts that similar physical stimuli (e.g., accent or ethnicity) could accentuate the feeling of belongingness to the same social group. Indeed, ethnicity provides visual cues to the extent of similarity (Rakić et al., 2011), and accent provides linguistic cues to social identities (Dragojevic and Giles, 2014). People who share the same languages tend to possess similar attributes such as accent, and have a strong likelihood that they share the same culture, ethnicity, and language environment (e.g., Jiang, 2000; Phinney et al., 2001; see Giles and Billings, 2004 for a review of how adults perceived others as having different personalities and physical appearances when the others speak a different accent than oneself). Transcription of the conversations between participants in our study revealed that the English-same language pairs were perceived to share more similar accents and language background than the English-different language pairs. This suggests that there are subtle cues that participants express and/or are picked up during the communicative and collaborative process that inform them about their partners' linguistic characteristics and language background. The self-categorization theory would argue that it is similarity in such characteristics that would in turn lead to greater affinity and affiliation toward the familiar-speaking other and facilitate the collaborative process.

The above argument has its roots from the notion that people naturally form social categories to help them understand and reason about others in the complex social world. Past studies that examine the various factors of similarity or diversity between group members on performance in problem-solving tasks suggest that the extent of saliency (in similarity or diversity) could enhance or undermine collaborative problem-solving. Past studies also showed that ingroup members tend to be more biased in resource distribution and empathic toward their own members than outgroup members (Allport, 1954; Tajfel et al., 1971; Xu et al., 2009). Language (and how it is spoken) is a rich source of information about the speaker's origins, group membership, social significance, and even social power (e.g., Fiske and Neuberg, 2013; Liberman et al., 2017; Fiske and Neuberg, 2013). Indeed, developmental literature has extensively demonstrated that sharing the same language and accent is a strong marker for people to relate well and affiliate with the other. Children tend to like, imitate, and learn from those who share the same native language or accent than those who do not (e.g., Akhtar et al., 2012; Kinzler et al., 2011; Kinzler et al., 2009). Thus, the explicit and implicit differences between people in a group, such as a common spoken language, accent, and ethnicity, could conjure up perceptions and expectations of social group membership that can influence the outcome of the various types of collaborative problem-solving tasks. Nonetheless, as this study was not designed to determine the exact mechanism through which sharing language has a positive effect on the collaborative problem-solving process, future studies should explore the possible underlying mechanism further (e.g., affiliation vs. efficiency of communication and collaboration). For example, participants' subjective perception of their team members in terms of affiliation, comfort, and ease of communication can be obtained and analyzed with objective measures of communication and collaboration, as well as with task performance outcomes.

One related question to ask is whether it is possible that the positive effects of speaking the same two languages in the collaborative problem-solving tasks were due to the English-same pairs speaking English as their first language and the Englishdifferent pairs speaking English as their second language. Individuals who speak English as their first language would likely share a more similar accent than those who speak English as a second language. As laid out earlier, such differences in accent between individuals could affect trust, feelings of affiliation and membership between them. Our independent coders did find that English-same language pairs sounded more similar in accent than English-different language pairs in both collaborative problemsolving tasks. In our study, there were 13 English-same pairs (out of 31) and 10 English-different pairs (out of 28) who spoke English as their first language. Chi-square test suggested that this distribution was not statistically significant $\left(X^{2}(2, N=59)=0.24\right.$, $p=0.62)$. The number of pairs who spoke English as their first language in the English-same condition did not differ significantly 
from the number of pairs who spoke English as their first language in the English-different condition. Furthermore, it was found that pairs who spoke English as their first language did not differ significantly in performance from pairs who did not speak English as their first language in the insight problem solving task $(F(1$, $\left.57)=0.001, p=0.97, \eta^{2}=0.00\right)$, the divergent thinking task $(F(1$, $\left.57)=3.77, p=0.06, \eta^{2}=0.06\right)$, communication and collaboration on the insight problem-solving task $(F(1,54)=0.40, p=0.53$, $\eta^{2}=0.01$, and $F(1,54)=0.17, p=0.68, \eta^{2}=0.003$, respectively), and communication and collaboration on the divergent thinking task $\left(F(1,54)=0.94, p=0.34, \eta^{2}=0.02\right.$, and $F(1,54)=1.00$, $p=0.32, \eta^{2}=0.02$, respectively). Thus, it is unlikely that the effects found in our study were explained by participants speaking English as their first language (or not) within their pairs. However, we noted the small sample size of pairs who spoke English as their first language, and we should exercise caution in making comparative conclusions at this point. Sharing the same first language remains an important factor, and future studies should control for this when examining the effects of sharing the same languages on collaborative problem-solving tasks.

In this study, we used two types of collaborative problemsolving tasks that required different levels of collaboration between pairs of participants-an insight problem-solving task (Triangle of Coins) and a divergent thinking task (Mind-mapping). Our results indicated that when the performance of a task would benefit from high levels of collaboration, such as the divergent thinking task (since idea generation via brain-storming discussions is the key performance outcome), the English-different language pairs took more turns in their interaction with each other than the Englishsame language pairs. When the performance of a task does not rely on high levels of collaboration, such as the insight problemsolving task, both pair types were similar in their turn-taking patterns. However collaborative problem solving is more than what these two types of task can measure. Hesse et al. (2015) suggested that collaborative problem solving can involve many sub-skills, such as social process skills, perspective taking skills, social regulation skills, cognitive process skills, etc. Different problem-solving tasks require different levels of coordinated effort by group members at the same time (e.g., Diehl and Stroebe, 1987; Karau and Williams, 1993; Stasser and Titus, 1985). Thus, future studies should consider exploring the effect of sharing the same languages on different types of collaborative problem-solving tasks that involve different types of sub-skills.

An important caveat for this study was the role of ethnicity in understanding the effects of sharing same languages on collaborative problem-solving tasks. In this study, all the English-same language pairs shared the same ethnicity compared to only half of the English-different language pairs (15 out of 28 pairs were of different ethnicity). The literature provides mixed results on the effects of sharing the same ethnicity on collaborative problemsolving. Sharing the same ethnicity might increase the comfort felt by participants in completing the task (McLeod et al., 1996; Terenzini et al., 2001; Wright and Lander, 2003). However, the same studies also showed that diversity rather than similarity, particularly in ethnicity, has positive effects on collaborative problem-solving tasks. In our study, pairs with different ethnicities were shown to communicate and collaborate more on the divergent thinking task than pairs with the same ethnicities, though direct effects of ethnicity on the insight problem solving task and divergent thinking task were not found. We acknowledge the difficulty of disentangling the effects of ethnicity in this study from sharing same languages as the effect of ethnicity could be due to similarities in appearance, accent, or language as well. Thus, we have tried to statistically control for it in our analysis:
English-same language pairs were found to do better in an insight problem-solving task than English-different language pairs after the difference in ethnicity within pairs and other factors were controlled for. Nonetheless, further work should try to tease these factors apart in order to have a better understanding of the effects of ethnicity and shared language on collaborative problem-solving.

\section{Conclusion}

Collaborative problem-solving has been found to be crucial in today's society with highly complex problems. Our study suggested that sharing the same languages could provide an additional pathway to boost collaborative problem-solving. Specifically, sharing the same languages could enhance performance in both collaborative insight problem-solving and divergent thinking tasks in multilingual teams potentially through better and more efficient communicative and collaborative processes. It is also possible that a greater affinity and affiliation toward the familiar-speaking other facilitated the collaborative process via factors such as accent and ethnicity. However, given the complexity of collaborative problem-solving in a variety of contexts, our study represents just a first step in this work. More studies are required to provide further insights on the facilitative and inhibitory effects of sharing same languages and other factors in collaborative problem-solving.

\section{Data availability}

The datasets generated during and/or analyzed during this study are not publicly available due confidentiality reasons but are available from the corresponding author on reasonable request.

Received: 24 June 2019; Accepted: 8 November 2019; Published online: 03 December 2019

\section{References}

Akhtar N, Menjivar J, Hoicka E, Sabbagh MA (2012) Learning foreign labels from a foreign speaker: the role of (limited) exposure to a second language. J Child Lang 39:1135-1149. https://doi.org/10.1017/S0305000911000481

Allport G (1954) The nature of prejudice. Addison Wesley, Reading

Arterberry ME, Cain KM, Chopko SA (2007) Collaborative problem-solving in five-year-old children: evidence of social facilitation and social loafing. Educ Psychol 27(5):577-596. https://doi.org/10.1080/01443410701308755

Baldo JV, Dronkers NF, Wilkins D, Ludy C, Raskin P, Kim J (2005) Is problemsolving dependent on language? Brain Lang 92(3):240-250. https://doi.org/ 10.1016/j.bandl.2004.06.103

Barron B (2000) Problem-solving in video-based microworlds: collaborative and individual outcomes of high-achieving sixth-grade students. J Educ Psychol 92(2):391. https://doi.org/10.1037/0022-0663.92.2.391

Bialystok E, Majumder S (1998) The relationship between bilingualism and the development of cognitive processes in problem solving. Appl Psycholinguist 19(1):69-85. https://doi.org/10.1017/S0142716400010584

Canham MS, Wiley J, Mayer RE (2012) When diversity in training improves dyadic problem solving. Appl Cogn Psychol 26(3):421-430. https://doi.org/ 10.1002/acp. 1844

Care E, Griffin P, Scoular C, Awwal N, Zoanetti N (2015) Collaborative problem solving tasks. In: Griffin P, Care E (eds) Assessment and teaching of 21st century skills. Educational assessment in an information age. Springer, Dordrecht

Crystal D (1997) English as a global language. Cambridge University Press, New York

Curşeu PL, Pluut H (2013) Student groups as learning entities: the effect of group diversity and teamwork quality on groups' cognitive complexity. Stud High Educ 38(1):87-103. https://doi.org/10.1080/03075079.2011.565122

Cushen PJ, Wiley J (2011) Aha! Voila! Eureka! Bilingualism and insightful problem solving. Learn Individ Differences 21(4):458-462. https://doi.org/10.1016/j. lindif.2011.02.007

Diehl M, Stroebe W (1987) Productivity loss in brainstorming groups: toward the solution of a riddle. J Personal Soc Psychol 53(3):497-509. https://doi.org/ $10.1037 / 0022-3514.53 .3 .497$ 
Dillenbourg P (1999) What do you mean by collaborative learning? Cogn Computat Approach 1:1-15

Dossick CS, Neff G (2011) Messy talk and clean technology: communication, problem-solving and collaboration using building information modelling. Eng Proj Organ J 1(2):83-93. https://doi.org/10.1080/21573727.2011.569929

Dragojevic M, Giles H (2014) Language and interpersonal communication: their intergroup dynamics. In: Berger CR (ed) Handbook of interpersonal communication. De Gruyter Mouton, Berlin, p 29-51

Edelsky C (1981) Who's got the floor? Lang Soc 10(03):383-421. https://doi.org/ $10.1017 / \mathrm{S} 004740450000885 \mathrm{X}$

Fiske ST, Neuberg SL (2013) Category-based and individuating processes as a function of information and motivation: evidence from our lab. In: Bar-Tal D et al. (eds) Sterotyping and prejudice: changing conceptions. Springer Science Press, p 83-104

Giles H, Billings AC (2004) Assessing language attitudes: speaker evaluation studies. In: Davies A, Elder C (eds) The handbook of applied linguistics. Blackwell Publishing, Oxford, p 187-209

Gluszek A, Dovidio JF (2010) The way they speak: a social psychological perspective on the stigma of nonnative accents in communication. Personal Soc Psychol Rev 14(2):214-237. https://doi.org/10.1177/1088868309359288

Halfhill T, Sundstrom E, Lahner J, Calderone W, Nielsen TM (2005) Group personality composition and group effectiveness an integrative review of empirical research. Small Group Res 36(1):83-105. https://doi.org/10.1177/ 1046496404268538

Harris A, Rick J, Bonnett V, Yuill N, Fleck R, Marshall P, Rogers Y (2009) Around the table: are multiple-touch surfaces better than single-touch for children's collaborative interactions? In: Proceedings of the 9th international conference on Computer supported collaborative learning. Vol. 1. International Society of the Learning Sciences, p 335-344

Harris A, Yuill N, Luckin R (2008) The influence of context-specific and dispositional achievement goals on children's paired collaborative interaction. $\mathrm{Br}$ J Educ Psychol 78(3):355-374. https://doi.org/10.1348/000709907X267067

Harrison DA, Klein KJ (2007) What's the difference? Diversity constructs as separation, variety, or disparity in organizations. Acad Manag Rev 32 (4):1199-1228. https://doi.org/10.5465/amr.2007.26586096

Harrison DA, Price KH, Gavin JH, Florey AT (2002) Time, teams, and task performance: changing effects of surface-and deep-level diversity on group functioning. Acad Manag J 45(5):1029-1045. https://doi.org/10.5465/3069328

Hayslip B, Sterns HL (1979) Age differences in relationships between crystallized and fluid intelligences and problem-solving. J Gerontol 34(3):404-414. https://doi.org/10.1093/geronj/34.3.404

Hesse F, Care E, Buder J, Sassenberg K, Griffin P (2015) A framework for teachable collaborative problem solving skills. In: Griffin P, Care E (eds) Assessment and teaching of 21st century skills. Educational Assessment in an information age. Springer, Dordrecht

Hoffman LR, Maier NRF (1961) Quality and acceptance of problem solving by members of homogenous and heterogenous groups. J Abnorm Soc Psychol 62:401-407. https://doi.org/10.1037/h0044025

Isaacs EA, Tang JC (1994) What video can and cannot do for collaboration: a case study. Multimed Syst 2(2):63-73. https://doi.org/10.1007/BF01274181

Jiang W (2000) The relationship between culture and language. ELT J 54 (4):328-334. https://doi.org/10.1093/elt/54.4.328

John OP, Srivastava S (1999) The Big-Five trait taxonomy: history, measurement, and theoretical perspectives. In: Pervin LA, John OP (eds) Handbook of personality: theory and research. Vol. 2 Guilford Press, New York, p 102-138

Kannampallil TG, Morrow, DG, Fu WT, Raquel, L, Muriset A (2016) Communication patterns in a collaborative medication scheduling task among older adults. In: Healthcare Informatics (ICHI), 2016 IEEE International Conference on IEEE. IEEE, $\mathrm{p}$ 367-374

Karau SJ, Williams KD (1993) Social loafing: a meta-analytic review and theoretical integration. J Personal Soc Psychol 65(4):681-706. https://doi.org/10.1037/ 0022-3514.65.4.681

Kempert S, Saalbach H, Hardy I (2011) Cognitive benefits and costs of bilingualism in elementary school students: the case of mathematical word problems. J Educ Psychol 103(3):547. https://doi.org/10.1037/a0023619

Kickul J, Neuman G (2000) Emergent leadership behaviors: the function of personality and cognitive ability in determining teamwork performance and KSAs. J Bus Psychol 15(1):27-51. https://doi.org/10.1023/A:1007714801558

Kinzler KD, Corriveau KH, Harries PL (2011) Children's selective trust in nativeaccented speakers. Developmental Sci 14:106-111. https://doi.org/10.1111/ j.1467-7687.2010.00965.x

Kinzler KD, Shutts K, DeJesus J, Spelke ES (2009) Accent trumps race in children's social preferences. Soc Cognition 27:623-634. https://doi.org/10.1521/ soco.2009.27.4.623

Klimoski R, Mohammed S (1994) Team mental model: contstruct or metaphor? J Manag 20:403-437. https://doi.org/10.1177/014920639402000206

Kruger AC (1993) Peer collaboration: conflict, cooperation, or both? Soc Dev 2 (3):165-182. https://doi.org/10.1111/j.1467-9507.1993.tb00012.x
Kurtzberg TR (2005) Feeling creative, being creative: an empirical study of diversity and creativity in teams. Creativity Res J 17(1):51-65. https://doi.org/10.1207/ s15326934crj1701_5

Kwon SY, Cifuentes L (2009) The comparative effect of individually-constructed vs. collaboratively-constructed computer-based concept maps. Computers Educ 52(2):365-375. https://doi.org/10.1016/j.compedu.2008.09.012

Li H, Xu J, Chen J, Fan Y (2015) A reliability meta-analysis for 44 items big five inventory: based on the reliability generalization methodology. Adv Psychological Sci 23(5):755-765. https://doi.org/10.3724/sp.j.1042.2015.00755

Liberman Z, Woodward AL, Kinzler KD (2017) Origins of social categorization. Trends Cogn Sci 21(7):556-568. https://doi.org/10.1016/j.tics.2017.04.004

Maltzman I, Eisman E, Brooks LO (1956) Some relationships between methods of instruction, personality variables, and problem-solving behavior. J Educ Psychol 47(2):71. https://doi.org/10.1037/h0048019

McLeod PL, Lobel SA, Cox Jr TH (1996) Ethnic diversity and creativity in small groups. Small Group Res 27(2):248-264. https://doi.org/10.1177/1046496496272003

Mercer N (1996) The quality of talk in children's collaborative activity in the classroom. Learn Instr 6(4):359-377. https://doi.org/10.1016/S0959-4752(96)00021-7

Neeley T, Hinds PJ, Cramton CD (2009) Walking through jelly: language proficiency, emotions, and disrupted collaboration in global work. Harvard Business School Organizational Behavior Unit Working Paper, (09-138). https://doi.org/10.2139/ssrn.1414343

Nelson LM (1999) Collaborative problem solving. In: Reigeluth CM (ed) Instructional design theories and models: a new paradigm of instructional theory. Vol. II. Lawrence Erlbaum Associates, Mahwah, p 241-267

Noels KA, Pon G, Clément R (1996) Language, identity, and adjustment: the role of linguistic self-confidence in the acculturation process. J Lang Soc Psychol 15 (3):246-264. https://doi.org/10.1177/0261927X960153003

Paradis M (1998) Language and communication in multilinguals. In: Handbook of neurolinguistics. Academic Press, p 417-430

Phelps E, Damon W (1989) Problem-solving with equals: peer collaboration as a context for learning mathematics and spatial concepts. J Educ Psychol 81 (4):639. https://doi.org/10.1037/0022-0663.81.4.639

Phinney JS, Romero I, Nava M, Huang D (2001) The role of language, parents, and peers in ethnic identity among adolescents in immigrant families. J Youth Adolescence 30(2):135-153. https://doi.org/10.1023/A:1010389607319

Rakić T, Steffens MC, Mummendey A (2011) Blinded by the accent! The minor role of looks in ethnic categorization. J Personal Soc Psychol 100:16-29. https://doi.org/10.1037/a0021522

Raven J, Raven JC, Court JH (2004) Manual for Raven's progressive matrices and vocabulary scales. Harcourt, San Antonio

Resnick LB, Glaser R (1976) Problem-solving and intelligence. In: Resnick LB (ed) The nature of intelligence. Erlbaum, Hillsdale, p 205-230

Rice ML, Smolik F, Perpich D, Thompson T, Rytting N, Blossom M (2010) Mean length of utterance levels in 6-month intervals for children 3 to 9 years with and without language impairments. J Speech Lang Hearing Res 53 (2):333-349. https://doi.org/10.1044/1092-4388(2009/08-0183)

Ripoll H, Kerlirzin Y, Stein JF, Reine B (1995) Analysis of information processing, decision making, and visual strategies in complex problem-solving sport situations. Hum Mov Sci 14(3):325-349. https://doi.org/10.1016/0167-9457 (95)00019-O

Roschelle J, Teasley SD (1995) The construction of shared knowledge in collaborative problem-solving. In: O'Malley C (ed) Computer supported collaborative learning. Springer, Berlin Heidelberg, p 69-97

Ross JA, Raphael D (1990) Communication and problem solving achievement in cooperative learning groups. J Curric Stud 22(2):149-164. https://doi.org/ $10.1080 / 0022027900220204$

Shepard CR (1964) Small groups. Chandler Publishing Co, San Francisco

Springer L, Stanne ME, Donovan SS (1999) Effects of small-group learning on undergraduates in science, mathematics, engineering, and technology: a meta-analysis. Rev Educ Res 69(1):21-51. https://doi.org/10.3102/ 00346543069001021

Srivathsavai R, Genco N, Hölttä-Otto K, Seepersad CC (2010) Study of existing metrics used in measurement of ideation effectiveness. In: ASME 2010 International Design Engineering Technical Conferences and Computers and Information in Engineering Conference. American Society of Mechanical Engineers, p 355-366

Staples DS, Zhao L (2006) The effects of cultural diversity in virtual teams versus face-to-face teams. Group Decis Negotiation 15(4):389-406. https://doi.org/ 10.1007/s10726-006-9042-x

Stasser G, Titus W (1985) Pooling of unshared information in group decision making: biased information sampling during discussion. J Personal Soc Psychol 48(6):1467-1478. https://doi.org/10.1037/0022-3514.48.6.1467

Strough J, Berg CA, Meegan SP (2001) Friendship and gender differences in task and social interpretations of peer collaborative problem-solving. Soc Dev 10 (1):1-22. https://doi.org/10.1111/1467-9507.00145

SUTD-MIT International Design Centre (2015) Concept generation tools-mind mapping [Video file]. https://www.youtube.com/watch?v=qYIQWTlmnhY 
Tajfel H, Flament C, Billig MG, Bundy RF (1971) Social categorization and intergroup behaviour. Eur J Soc Psychol 1:149-177. https://doi.org/10.1002/ ejsp.2420010202

Terenzini PT, Cabrera AF, Colbeck CL, Bjorklund SA, Parente JM (2001) Racial and ethnic diversity in the classroom: does it promote student learning? J Higher Educ 509-531. https://doi.org/10.2307/2672879

Thornburg TH (1991) Group size and member diversity influence on creative performance. J Creative Behav 25(4):324-333. https://doi.org/10.1002/j.21626057.1991.tb01145.x

Turner JC (1985) Social categorization and the self-concept: a social cognitive theory of group behaviour. In: Lawler EJ (ed) Advances in group processes: theory and research. Vol. 2. JAI Press, Greenwich

Turner JC, Hogg MA, Oakes PJ, Reicher SD, Wetherell M (1987) Rediscovering the social group: a self-categorization theory. Blackwell, Oxford/New York

U. S. Census Bureau (2010) The 2011 Statistical abstract. Languages spoken at home by language: 2008, Table 53. http://www.census.gov/compendia/ statab/cats/population/ancestry_language_spoken_at_home.html. Accessed 4 Aug 2011

Villa RA, Thousand JS, Nevin AI, Malgeri C (1996) Instilling collaboration for inclusive schooling as a way of doing business in public schools. Remedial Spec Educ 17(3):169-181. https://doi.org/10.1177/074193259601700306

Webb N (1984) Sex differences in interaction and achievement in cooperative small groups. J Educ Psychol 76:33-44. https://doi.org/10.1037/0022-0663.76.1.33

Webb NM, Troper JD, Fall R (1995) Constructive activity and learning in collaborative small groups. J Educ Psychol 87(3):406. https://doi.org/10.1037/ 0022-0663.87.3.406

Woodman RW, Sawyer JE, Griffin RW (1993) Toward a theory of organizational creativity. Acad Manag Rev 18(2):293-321. https://doi.org/10.5465/ AMR.1993.3997517

Woolley AW, Gerbasi ME, Chabris CF, Kosslyn SM, Hackman JR (2008) Bringing in the experts: how team composition and collaborative planning jointly shape analytic effectiveness. Small Group Res 39(3):352-371. https://doi.org/ $10.1177 / 1046496408317792$

Wright S, Lander D (2003) Collaborative group interactions of students from two ethnic backgrounds. High Educ Res Dev 22(3):237-251. https://doi.org/ $10.1080 / 0729436032000145121$

Xu X, Zuo X, Wang X, Han S (2009) Do you feel my pain? Racial group membership modulates empathic neural responses. J Neurosci 29(26):8525-8529. https://doi.org/10.1523/JNEUROSCI.2418-09.200

\section{Acknowledgements}

We are grateful to the participants who participated in the study. We thank Stephanie Diez, Adam Oei, Yu Shaun Lim, Shirlyn Sia, and the Language and Social Cognition Lab members for their ideas and help in data collection and coding of mind-maps and audio recordings. Portions of this work were previously presented at the International Congress of Psychology 2016, and the International Conference on Applied Psychology 2016. This work was partially supported by the SUTD-MIT IDC grant (IDG31100106 and IDD41100104) and MOE Tier 1 grant (SUTDT12015007) awarded to the first author.

\section{Competing interests}

The authors declare no competing interests.

\section{Additional information}

Correspondence and requests for materials should be addressed to W.Q.Y.

Reprints and permission information is available at http://www.nature.com/reprints

Publisher's note Springer Nature remains neutral with regard to jurisdictional claims in published maps and institutional affiliations.

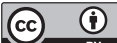

Open Access This article is licensed under a Creative Commons Attribution 4.0 International License, which permits use, sharing, adaptation, distribution and reproduction in any medium or format, as long as you give appropriate credit to the original author(s) and the source, provide a link to the Creative Commons license, and indicate if changes were made. The images or other third party material in this article are included in the article's Creative Commons license, unless indicated otherwise in a credit line to the material. If material is not included in the article's Creative Commons license and your intended use is not permitted by statutory regulation or exceeds the permitted use, you will need to obtain permission directly from the copyright holder. To view a copy of this license, visit http://creativecommons.org/ licenses/by/4.0/

(C) The Author(s) 2019 